\title{
Concomitant injuries may not reduce the likelihood of achieving symmetrical muscle function one year after anterior cruciate ligament reconstruction: a prospective observational study based on 263 patients
}

\author{
Eric Hamrin Senorski ${ }^{1,2}$ (E) Eleonor Svantesson ${ }^{3} \cdot$ Susanne Beischer ${ }^{1,2} \cdot$ Christoffer Thomeé $^{2} \cdot$ Alberto Grassi $^{4}$. \\ Ferid Krupic ${ }^{3} \cdot$ Roland Thomeé $^{1,2} \cdot$ Jón Karlsson ${ }^{3,5} \cdot$ Kristian Samuelsson $^{3,5}$
}

Received: 11 January 2018 / Accepted: 24 January 2018 / Published online: 5 February 2018

(c) The Author(s) 2018. This article is an open access publication

\begin{abstract}
Purpose A better understanding of patient characteristics and the way common concomitant injuries affect the recovery of muscle function after surgery should help providers to treat patients with anterior cruciate ligament (ACL) injuries. The aim of this study was to determine whether patient characteristics, concomitant injuries and graft choice at ACL reconstruction were associated with symmetrical knee muscle function at one year. The hypothesis was that the presence of concomitant injuries would negatively influence the opportunity to achieve symmetrical knee function at the one-year follow-up.

Methods Data was extracted from the Swedish National Knee Ligament Register and a rehabilitation outcome register between August 2012 and December 2016. The patients had been evaluated with a battery of tests comprising knee extension and flexion strength, vertical jump, hop for distance and the side-hop test one year after ACL reconstruction. Univariable and multivariable logistic regression analyses were performed with achieving a limb symmetry index (LSI) of $\geq 90 \%$ in all tests of muscle function as primary outcome.

Results A total of 263 patients with a mean age of $26.7 \pm 10.3$ years were included in the study ( $47 \%$ females). No patient demographic or intra-operative predictors were found to be significant when attempting to predict the achievement of a symmetrical muscle function. Lateral meniscus injury and a patellar tendon autograft reduced the odds of achieving an LSI of $\geq 90 \%$ in knee extension strength, $\mathrm{OR}=0.49$ [(95\% CI 0.25-0.97), $p=0.039$ ] and $\mathrm{OR}=0.30$ [(95\% CI 0.14-0.67), $p=0.0033$ ] respectively. In addition, reduced odds of recovering knee extension strength were found in older patients, OR $=0.76$ [( $95 \% \mathrm{CI}$ $0.60-0.98), p=0.034]$. A higher pre-injury level of physical activity increased the odds of recovering knee flexion strength, $\mathrm{OR}=1.14$ [(95\% CI 1.01-1.29), $p=0.037]$.

Conclusion Intra-operatively identified concomitant injuries or graft choice did not affect the likelihood of recovering symmetrical performance in five different tests of muscle function one year after ACL reconstruction. However, fewer than one in four patients achieved an LSI of $\geq 90 \%$ in all tests.
\end{abstract}

Level of evidence Prospective observational study: Level 2.

Keywords Anterior cruciate ligament $\cdot \mathrm{ACL} \cdot$ Reconstruction $\cdot$ Graft $\cdot$ Limb symmetry index $\cdot$ LSI $\cdot$ Rehabilitation · Register $\cdot$ Muscle function $\cdot$ Sports

\section{Introduction}

Electronic supplementary material The online version of this article (https://doi.org/10.1007/s00167-018-4845-2) contains supplementary material, which is available to authorized users.

Eric Hamrin Senorski

eric.hamrin.senorski@gu.se

Extended author information available on the last page of the article
Sustaining an injury to the anterior cruciate ligament (ACL) is something that is dreaded, especially among active athletes. However, it is well recognised that, in most cases, the current treatment for ACL tears successfully returns patients to their pre-injury level $[19,26,37]$. This in turn motivates most patients to strive for their desired comeback and work 
through a long period of rehabilitation. While the patient is frequently eager to return to sport (RTS), physicians and physiotherapists have important roles in guiding the patient in his or her decisions and determine readiness based on several important aspects [6]. However, RTS criteria are a complex area after ACL reconstruction and there is still no consensus on how best to determine when a patient is ready for an RTS $[3,7,34]$. One contributing explanation is that the isolated ACL injury is uncommon and the injury is instead frequently accompanied by injuries to other tissues, including articular cartilage, bone, collateral ligaments and menisci [29].

Tests of muscle function are often part of the evaluation prior to RTS and the achieved level of muscle function has been chosen as an important aspect to consider [12, 36]. When evaluating muscle function, the limb symmetry index (LSI) is the most established method. It is defined by comparing the result for the injured leg with that of the uninjured leg. It has been suggested that achieving a sufficient LSI will minimise the risk of sustaining a new injury and prevent the overuse of the other leg when returning to strenuous activity [25, 34]. However, there is limited previous research on understanding the effect of concomitant knee injuries and the ability to recover symmetrical knee function in patients after an ACL reconstruction.

A better understanding of patient characteristics and the way concomitant injuries affect the recovery of muscle function during the first year after surgery should help providers to treat patients with ACL injuries. The purpose of this study was, therefore, to determine whether patient characteristics, intra-operatively identified concomitant injuries and graft choice at primary ACL reconstruction were associated with the recovery of muscle function one year after reconstruction. Based on clinical experience, the hypothesis was that the presence of concomitant injuries would negatively influence the opportunity to achieve symmetrical knee function at the one-year follow-up.

\section{Materials and methods}

This cohort study was based on prospectively collected data from two registers; one rehabilitation specific (Project ACL) and one surgeon specific (the Swedish National Knee Ligament Register, SNKLR). Project ACL [14] uses a web-based database for regular assessment with patient-reported outcomes and tests of muscle function for patients with an ACL injury. Assessments are performed after a predefined followup schedule after the index ACL injury or reconstructive surgery. The battery of tests for muscle function is conducted according to a standardised protocol and comprises an evaluation of knee strength and hop performance based on previous publications $[13,23]$. At the start of the project from
September 2014, isometric strength tests were performed using the David F200 and F300 DMS-EVE (David Health Solutions Ltd, 2013, Finland) and these results contribute to approximately $35 \%$ of the total strength data. The isometric test evaluated peak torque in knee extension at $60^{\circ}$ of knee flexion and knee flexion at $30^{\circ}$ of flexion. From December 2015 , strength measurements were performed with a concentric isokinetic test of knee extension and knee flexion at 90 degrees per second using a Biodex System 4 (Biodex Medical Systems, Shirley, New York, USA) [36]. Both the isokinetic and isometric testing of knee extension and knee flexion strength has repeatedly been reported with excellent reliability, interclass correlation coefficient 0.95-0.99 and $0.93-0.99$, respectively $[2,8,31,32]$. Hop tests include a one-legged hop for distance, vertical jump (Muscle lab, Ergotest Technology, Oslo, Norway) and side-hop test. For the vertical hop and the hop for distance, the patients performed three to five practice trials, followed by three maximum trials. One attempt is allowed in the side-hop test and it was performed by the patients jumping as many times as possible over two lines $40 \mathrm{~cm}$ apart for $30 \mathrm{~s}$. Three minutes of rest were given between legs for the side-hop test [23]. All the hop tests were performed with the patients holding their hands behind their back and the best of three attempts was recorded.

The SNKLR is a nationwide database that utilises a webbased protocol for the collection of data [1, 17]. The protocol consists of two parts; one surgeon-reported section and one patient-reported section. The operating surgeon enters information about the activity performed at the time of injury, the time from injury to reconstruction, graft selection and surgical fixation techniques. All surgical procedures performed on the injured knee, including meniscal surgery and treatment for chondral lesions, are reported. Revisions and repeated surgery for other reasons are registered as separate entries in the register [9].

\section{Patients}

Patients in Project ACL with results from the one-year follow-up after reconstruction were eligible for inclusion. For these patients, additional intra-operative and surgical information was extracted from the SNKLR, including data on concomitant injuries and graft choice. Only patients who underwent primary unilateral ACL reconstruction and had undergone no previous knee surgery were included in the study. Patients were excluded if they had an early postoperative infection. All patients underwent an individualised criteria-based rehabilitation at their respective physiotherapy clinic. The patients received written information about the study and informed consent was obtained from included patients. Ethical approval was obtained from the Regional 
Ethical Review Board in Gothenburg (registration number 265-13, T023-17).

\section{Outcome}

The LSI was used to analyse the results of the tests of muscle function and was calculated as:

Limb symmetry index $(\%)=\frac{\text { Result for injured leg }}{\text { Result for uninjured leg }} \times 100$

Patients who had results from all five tests of muscle function at the 1-year follow-up were included in the primary analysis of the study. The LSI was analysed dichotomously where patients achieving an LSI of $\geq 90 \%$ in all tests of muscle function were compared with patients not achieving this cut-off value. This cut-off is based on the recommendation from the European Board of Sports Rehabilitation [34] and achieving this cut-off has been reported to decrease the risk of subsequent ACL injury after returning to sport $[12,18]$. Secondary analyses were performed for the knee extension and flexion strength tests with all results available from the one-year follow-up. An LSI of $\geq 90 \%$ for each test was used as a cut-off for the analyses.

\section{Statistical analysis}

Statistical analysis was performed using the statistical analysis system, SAS System for Windows, version 9 (SAS Institute Inc., Cary, North Carolina, USA). Descriptive statistics for patient demographics and outcomes were reported as numbers and percentages for categorical variables. Continuous variables were reported as the mean, standard deviation, [28] median, first and third quartile. For comparisons between two groups, Fisher's exact test (lowest one-sided $p$ value multiplied by 2) was used for dichotomous variables and the Mann-Whitney $U$ test for continuous variables. Binary logistical regression was performed to analyse the association between predictors and recovery of muscle function. For the primary analysis, the recovery of muscle function was defined as achieving an LSI of $\geq 90 \%$ in all the tests of muscle function and was used as a dependent variable. The presence of concomitant injuries was used dichotomously (yes/no) as an independent variable in the regression. Graft choice was analysed by comparing hamstring tendon (HT) and patellar tendon (PT) autografts. Patient demographics for gender, age (per 10 years), weight, height, body mass index and pre-injury level of physical activity measured using the Tegner activity score [33] were included as independent variables. The results from the logistic regression models were presented with the odds ratio (OR), 95\% confidence intervals (CI) and $p$ values. The area under the receiver operating characteristics (ROC) curve was given as a measurement of goodness of fit. In addition, sensitivity analyses were performed by calculating the association of concomitant injuries and the recovery of symmetrical strength in knee extension and flexion, also defined as $\geq 90 \%$ in LSI. Finally, in an attempt to find the best predictive model for achieving an LSI of $\geq 90 \%$ in all the tests of muscle function, knee extension strength and knee flexion strength, a step-wise multivariable logistic model was used. Multivariable analyses were performed for muscle function tests that had at least one significant outcome in the univariable analyses. Predictors with $p<0.20$ were entered into the step-wise analyses. All significance tests were two-sided and conducted at the 5\% significance level.
Fig. 1 Flow chart of included and excluded PRO; patientreported outcome

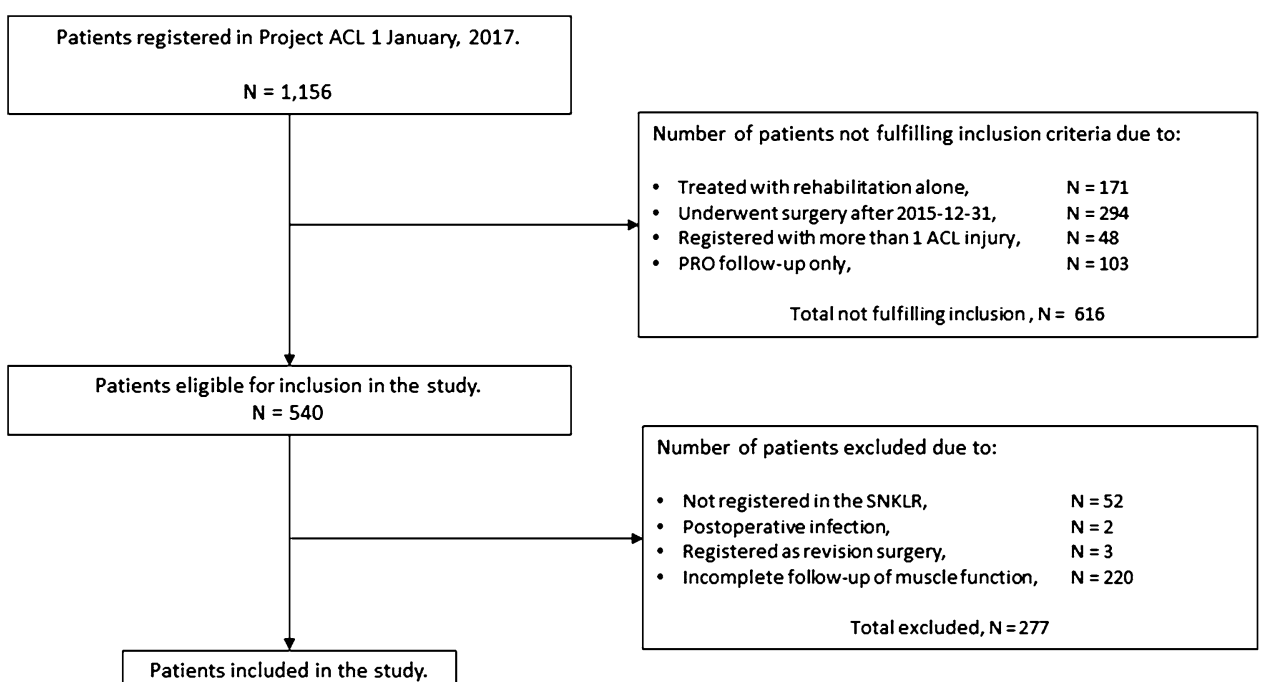

$N=263$ 


\section{Results}

A total of 263 patients fulfilled the inclusion criteria for the study (Fig. 1). Patient sex was evenly distributed in the cohort, 124 patients (47\%) were females. The average age at ACL reconstruction among the included patients was $28 \pm 10$ years. A total of $89 \%$ of the cohort received a hamstring tendon autograft and the most common activity that led to ACL injury was football. A meniscus injury was the most common concomitant injury in the cohort (44\%). Patient demographics and a drop-out analysis are presented in Table 1. No differences in baseline demographics, the presence of concomitant injuries or the pre-injury level of physical activity were found for included and excluded patients. The results from the 1-year follow-up of muscle function are available in Supplementary Table 1.

Table 1 Baseline data and drop-out analysis

$\begin{array}{lllll}\text { Not recovered }(n=166) & \text { Recovered, LSI } \geq 90 \% & \text { Total cohort }(n=263) & \text { Excluded }(n=277) & p \text { value }\end{array}$ in all five tests $(n=47)$

\begin{tabular}{|c|c|c|c|c|c|}
\hline \multicolumn{6}{|l|}{ Patient demographics } \\
\hline \multicolumn{6}{|l|}{ Patient sex } \\
\hline Female & $75(45.2 \%)$ & $17(36.2 \%)$ & $124(47.1 \%)$ & $154(55.6 \%)$ & \\
\hline Male & $91(54.8 \%)$ & $30(63.8 \%)$ & $139(52.9 \%)$ & $123(44.4 \%)$ & n.s \\
\hline Age at index ACL injury & $\begin{array}{l}26.1(9.6) \\
24.0(11.5 ; 54.5) \\
(18.3 ; 30.5) \\
n=166\end{array}$ & $\begin{array}{l}25.8(9.4) \\
24.1(13.2 ; 54.7) \\
(19.7 ; 28.3) \\
n=47\end{array}$ & $\begin{array}{l}26.7(10.3) \\
24.4(11.5 ; 57.7) \\
n=263\end{array}$ & $\begin{array}{l}26.5(10.3) \\
23.3(9.9 ; 61.0) \\
n=276\end{array}$ & n.s \\
\hline Age at index ACL reconstruction & $\begin{array}{l}27.5(10.0) \\
25.9(12.0 ; 55.9) \\
(19.8 ; 33.7) \\
n=166\end{array}$ & $\begin{array}{l}26.4(9.4) \\
24.3(13.7 ; 55.0) \\
(20.7 ; 29.6) \\
n=47\end{array}$ & $\begin{array}{l}28.0(10.5) \\
26.0(12.0 ; 58.4) \\
n=263\end{array}$ & $\begin{array}{l}27.1(10.3) \\
23.9(12.0 ; 57.3) \\
n=277\end{array}$ & n.s \\
\hline Height $(\mathrm{cm})$ & $\begin{array}{l}174.4(9.4) \\
175.0(167.0 ; 182.0) \\
n=160\end{array}$ & $\begin{array}{l}177.8(9.2) \\
178.0(170.0 ; 184.0) \\
n=46\end{array}$ & $\begin{array}{l}174.8(9.6) \\
175.0(151.0 ; 200.0) \\
n=263\end{array}$ & $\begin{array}{l}174.4(9.1) \\
174.0(140.0 ; 200.0) \\
n=277\end{array}$ & n.s \\
\hline Weight (kg) & $\begin{array}{l}74.0(16.1) \\
74.0(64.9 ; 83.0) \\
n=166\end{array}$ & $\begin{array}{l}75.1(15.8) \\
76.0(70.0 ; 81.9) \\
n=47\end{array}$ & $\begin{array}{l}73.7(13.0) \\
73.0(42.0 ; 114.0) \\
n=263\end{array}$ & $\begin{array}{l}73.5(13.5) \\
72.0(35.0 ; 130.0) \\
n=275\end{array}$ & n.s \\
\hline BMI $\left(\mathrm{kg} / \mathrm{m}^{2}\right)$ & $\begin{array}{l}24.4(4.5) \\
23.8(22.4 ; 25.8) \\
n=160\end{array}$ & $\begin{array}{l}24.2(2.3) \\
24.2(22.5 ; 25.2) \\
n=46\end{array}$ & $\begin{array}{l}24.1(2.8) \\
23.7(16.4 ; 38.7) \\
n=263\end{array}$ & $\begin{array}{l}24.1(3.2) \\
23.6(17.9 ; 38.0) \\
n=275\end{array}$ & n.s \\
\hline \multicolumn{6}{|l|}{ Surgery-related factors } \\
\hline \multicolumn{6}{|l|}{ Graft choice } \\
\hline Hamstring tendon & $143(86.7 \%)$ & $44(93.6 \%)$ & $232(88.9 \%)$ & $154(90.1 \%)$ & \\
\hline Patellar tendon & $22(13.3 \%)$ & $3(6.4 \%)$ & $29(11.1 \%)$ & $17(9.9 \%)$ & n.s \\
\hline \multicolumn{6}{|l|}{ Concomitant injuries } \\
\hline Medial meniscus & $31(18.7 \%)$ & $10(21.3 \%)$ & $57(21.7 \%)$ & $43(24.3 \%)$ & n.s \\
\hline Lateral meniscus & $47(28.3 \%)$ & $14(29.8 \%)$ & $72(27.4 \%)$ & $53(29.9 \%)$ & n.s \\
\hline Articular cartilage & $41(24.7 \%)$ & $15(31.9 \%)$ & $75(27.0 \%)$ & $47(26.9 \%)$ & n.s \\
\hline Medial collateral ligament & $7(4.2 \%)$ & $3(6.4 \%)$ & $13(4.9 \%)$ & $11(6.2 \%)$ & n.s \\
\hline Lateral collateral ligament & $0(0.0 \%)$ & $1(2.1 \%)$ & $1(0.4 \%)$ & $2(1.1 \%)$ & n.s \\
\hline Meniscus (medial or lateral) & $70(42.2 \%)$ & $23(48.9 \%)$ & $116(44.1 \%)$ & $82(46.3 \%)$ & n.s \\
\hline \multicolumn{6}{|l|}{ Activity } \\
\hline Football & $67(40.1 \%)$ & $24(49.0 \%)$ & $105(39.9 \%)$ & $107(45.5 \%)$ & n.s \\
\hline Tegner activity level $_{\text {preop }} \geq 6$ & $128(80.0 \%)$ & $39(84.8 \%)$ & $198(78.0 \%)$ & $98(85.2 \%)$ & n.s \\
\hline
\end{tabular}

For categorical variables, $n(\%)$ is presented

For continuous variables, the mean $(\mathrm{SD}) /$ median $(\mathrm{Q} 1 ; \mathrm{Q} 3) / n=$ is presented

For comparisons between groups, Fisher's exact test (lowest one-sided $p$ value multiplied by 2 ) was used for dichotomous variables and the Mann-Whitney $U$ test was used for continuous variables

$A C L$ anterior cruciate ligament, $B M I$ body mass index, $L S I$ limb symmetry index 
No patient demographic or intra-operative predictors were found to be statistically significant when attempting to predict achieving an LSI of $\geq 90 \%$ in all five tests of muscle function (Table 2; Fig. 2).
In the univariable analysis aiming to predict the achievement of an LSI $\geq 90 \%$ in knee extension strength, the absence of a lateral meniscus (LM) injury was associated with decreased $\mathrm{OR}=0.51$ [(95\% CI 0.27-0.99), $p=0.048]$.

Table 2 Univariable logistic regression model with a limb symmetry index of $\geq 90 \%$ in all five tests of muscle function as dependent outcome

\begin{tabular}{|c|c|c|c|c|c|c|}
\hline Predictors & $n$ missing & Value & Recovered "Yes" & $\begin{array}{l}\text { OR }(95 \% \mathrm{CI}) \\
\text { muscle recovery (all } \\
\mathrm{LSI} \geq 90 \%)\end{array}$ & $p$ value & $\begin{array}{l}\text { Area under ROC } \\
\text { curve }(95 \% \mathrm{CI})\end{array}$ \\
\hline \multicolumn{7}{|l|}{ Concomitant injuries } \\
\hline \multirow[t]{2}{*}{ Medial meniscus } & 0 & Yes & $10(24.4 \%)$ & & & \\
\hline & & No & $37(21.5 \%)$ & $0.85(0.38-1.89)$ & n.s & $0.51(0.45-0.58)$ \\
\hline \multirow[t]{2}{*}{ Lateral meniscus } & 0 & Yes & $14(23.0 \%)$ & & & \\
\hline & & No & $33(21.7 \%)$ & $0.93(0.46-1.89)$ & n.s & $0.51(0.43-0.58)$ \\
\hline \multirow[t]{2}{*}{ Articular cartilage } & 0 & Yes & $15(26.8 \%)$ & & & \\
\hline & & No & $32(20.4 \%)$ & $0.70(0.34-1.42)$ & n.s & $0.54(0.46-0.61)$ \\
\hline \multirow[t]{2}{*}{ Medial collateral ligament } & 0 & Yes & $3(30.0 \%)$ & & & \\
\hline & & No & $44(21.7 \%)$ & $0.65(0.16-2.60)$ & n.s & $0.51(0.47-0.55)$ \\
\hline \multirow[t]{2}{*}{ Lateral collateral ligament } & 0 & Yes & $1(100.0 \%)$ & & & \\
\hline & & No & $46(21.7 \%)$ & 0.00 (0.00-infinity) & n.s & $0.51(0.49-0.53)$ \\
\hline \multirow[t]{2}{*}{ Meniscus (medial or lateral) } & 0 & Yes & $23(24.7 \%)$ & & & \\
\hline & & No & $24(20.0 \%)$ & $0.76(0.40-1.46)$ & n.s & $0.53(0.45-0.62)$ \\
\hline \multicolumn{7}{|l|}{ Surgery-related factors } \\
\hline \multirow[t]{2}{*}{ Graft choice } & 7 & Hamstring tendon & $44(23.5 \%)$ & & & \\
\hline & & Patellar tendon & $3(12.0 \%)$ & $0.44(0.13-1.55)$ & n.s & $0.53(0.49-0.58)$ \\
\hline \multicolumn{7}{|l|}{ Patient demographics } \\
\hline \multirow{3}{*}{$\begin{array}{l}\text { Age at index ACL reconstruction (OR } \\
\text { per } 10 \text { units) }\end{array}$} & 0 & $12-<25$ & $25(24.3 \%)$ & & & \\
\hline & & $25-<35$ & $15(21.7 \%)$ & & & \\
\hline & & $35-58$ & $7(17.1 \%)$ & $0.89(0.63-1.25)$ & n.s & $0.53(0.44-0.62)$ \\
\hline \multirow[t]{2}{*}{ Patient sex } & 0 & Female & $17(18.5 \%)$ & & & \\
\hline & & Male & $30(24.8 \%)$ & $1.45(0.75-2.84)$ & n.s & $0.55(0.47-0.62)$ \\
\hline \multirow{5}{*}{$\begin{array}{l}\text { Tegner activity level pre-operative } \\
\quad(0-10)\end{array}$} & 9 & $1-6$ & $11(19.0 \%)$ & & & \\
\hline & & 7 & $9(27.3 \%)$ & & & \\
\hline & & 8 & $6(12.8 \%)$ & & & \\
\hline & & 9 & $15(31.3 \%)$ & & & \\
\hline & & 10 & $5(25.0 \%)$ & $1.08(0.92-1.27)$ & n.s & $0.55(0.45-0.64)$ \\
\hline \multirow[t]{3}{*}{ Height $(\mathrm{cm})(\mathrm{OR}$ per 10 units) } & 0 & $151-<170$ & $11(16.2 \%)$ & & & \\
\hline & & $170-<180$ & $16(23.5 \%)$ & & & \\
\hline & & $180-200$ & $20(26.0 \%)$ & $1.41(0.99-2.00)$ & n.s & $0.58(0.49-0.67)$ \\
\hline \multirow[t]{3}{*}{ Weight (kg) (OR per 10 units) } & 0 & $42-<67$ & $13(18.3 \%)$ & & & \\
\hline & & $67-<79$ & $19(26.0 \%)$ & & & \\
\hline & & $79-114$ & $15(21.7 \%)$ & $1.15(0.89-1.48)$ & n.s & $0.54(0.45-0.63)$ \\
\hline \multirow[t]{3}{*}{ BMI $\left(\mathrm{kg} / \mathrm{m}^{2}\right)$} & 0 & $16-<23$ & $23(26.4 \%)$ & & & \\
\hline & & $23-<25$ & $9(14.1 \%)$ & & & \\
\hline & & $25-39$ & $15(24.2 \%)$ & $0.99(0.87-1.12)$ & n.s & $0.52(0.43-0.61)$ \\
\hline
\end{tabular}

"Yes/No" indicates the presence of the described concomitant injury

All tests were performed with univariable logistic regression

$p$ values, $\mathrm{OR}$ and area under ROC curve were based on original values and not on stratified groups

OR is the ratio for the odds of an increase in the predictor of one unit

$A C L$ anterior cruciate ligament, $O R$ odds ratio, $C I$ confidence interval, $R O C$ receiver operating characteristic 
Fig. 2 Odds ratio (OR), 95\% confidence intervals and area under the curve from the receiver operating characteristic for a limb symmetry index of $\geq 90 \%$ in all five tests strength. An OR of $>1$ indicates a result favouring the absence of a concomitant injury. For graft choice, an OR of $<1$ indicates that the result favours a hamstring tendon autograft, while an OR of $>1$ favours a patellar tendon autograft

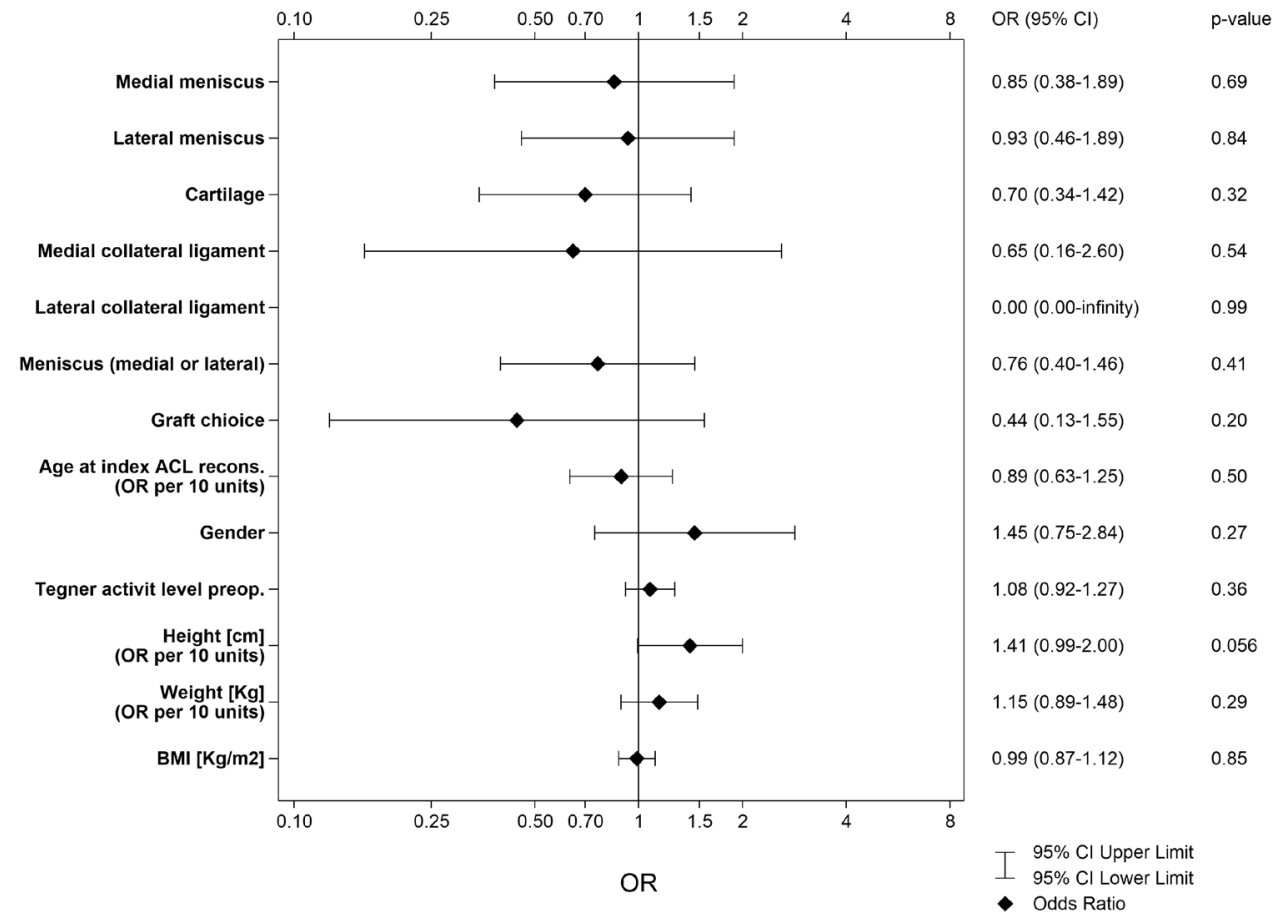

In addition, a PT autograft and older age decreased the odds of achieving an LSI of $\geq 90 \%$ in knee extension strength, $\mathrm{OR}=0.32$ [(95\% CI 0.15-0.70), $p=0.0043]$ and $\mathrm{OR}=0.76$ $[(0.60-0.98), p=0.034]$ respectively. The absence of a concomitant LM injury, PT autograft and older age were also found to decrease the odds in the multivariable analysis, $\mathrm{OR}=0.51$ [(95\% CI 0.25-0.99), $p=0.048]$, OR $=0.24$ [(95\% CI $0.10-0.55), p=0.0008]$ and $\mathrm{OR}=0.73[(95 \% \mathrm{CI}$ $0.56-0.94), p=0.017$ ] (Table 3 and Supplementary Tables 2 and 3). A higher pre-injury level of physical activity was the only predictor found to be significant when attempting to predict achieving an LSI of $\geq 90 \%$ in knee flexion strength, $\mathrm{OR}=1.14$ [(95\% CI 1.01-1.29), $p=0.037]$ (Table 4 and Supplementary Tables 4 and 5).

\section{Discussion}

The primary finding in the present study was that patients with and without concomitant intra-articular injuries had comparable odds of achieving an LSI of $\geq 90 \%$ in five tests of muscle function one year after ACL reconstruction. It is noteworthy that only $23 \%$ of patients achieved symmetrical function in all the performed tests. In the analysis of knee extension strength, patients who received an HT autograft and had an LM injury had favourable odds of achieving symmetrical strength. In addition, a small favourable effect was found for younger age. However, it is important to remember that all the logistic regression models resulted at best in a poor goodness of fit, which indicates that other factors that were not included in the analyses contribute to achieving a symmetrical performance across a battery of tests.

Remarkably, over $75 \%$ of patients were not able to achieve symmetrical results in all five tests of muscle function one year after surgery (Table 1 and Supplementary Table 1). This confirms previous findings in the scientific literature and implies that restoring muscular capacity may take longer than the 9-12 months that is commonly used as a reference $[7,11,35,38,41]$ and therefore may have important indications for RTS [12].

The presence of concomitant injuries was not associated with the recovery of muscle function in this study, which can be due to that one year is a sufficient timeframe to recover from the short-term impairment caused by concomitant injuries or due to the limited sensory innervation of these structures misleading the perceptions of the severity of these injuries [4, 5, 10, 22, 39]. However, it is well known that the presence of a concomitant injury is associated with a long-term risk of impaired knee function [27]. Degenerative changes in joints, such as osteoarthritis, take time to develop and it is currently not known if the risk of these changes or their impairment can be reduced by achieving symmetrical knee function [30]. The lack of association found in this study questions whether other factors are equally or more important to include obtaining a complete understanding of what affects the recovery of muscle function after ACL reconstruction, e.g. psychological characteristics and preoperative or early post-operative knee function. However, the lack of an association between concomitant injuries and the recovery of muscle function may also be contributed 
Table 3 Univariable and multivariable logistic regression model with a limb symmetry index of $\geq 90 \%$ in the knee extension test as dependent outcome

\begin{tabular}{|c|c|c|c|c|c|c|c|c|}
\hline \multirow[t]{2}{*}{ Predictors } & \multirow[t]{2}{*}{$n$ missing } & \multirow[t]{2}{*}{ Value } & \multirow[t]{2}{*}{ Recovered "Yes" } & \multicolumn{3}{|l|}{ Univariable* } & \multicolumn{2}{|l|}{ Multivariable*** } \\
\hline & & & & $\begin{array}{l}\text { OR }(95 \% \mathrm{CI}) \\
\text { LSI knee exten- } \\
\text { sion } \geq 90 \%\end{array}$ & $p$ value & $\begin{array}{l}\text { Area under ROC } \\
\text { curve }(95 \% \mathrm{CI})\end{array}$ & $\begin{array}{l}\text { OR }(95 \% \text { CI }) \\
\text { LSI knee exten- } \\
\text { sion } \geq 90 \%\end{array}$ & $p$ value \\
\hline \multicolumn{9}{|c|}{ Concomitant injuries } \\
\hline \multirow{2}{*}{$\begin{array}{l}\text { Medial menis- } \\
\text { cus }\end{array}$} & 0 & Yes & $37(64.9 \%)$ & & & & & \\
\hline & & No & $151(73.3 \%)$ & $1.48(0.79-2.77)$ & n.s & $0.53(0.48-0.59)$ & & \\
\hline \multirow{2}{*}{$\begin{array}{l}\text { Lateral menis- } \\
\text { cus }\end{array}$} & 0 & Yes & $58(80.6 \%)$ & & & & & \\
\hline & & No & $130(68.1 \%)$ & $0.51(0.27-0.99)$ & 0.048 & $0.56(0.51-0.62)$ & $0.50(0.25-0.99)$ & 0.049 \\
\hline \multirow{2}{*}{$\begin{array}{l}\text { Articular carti- } \\
\text { lage }\end{array}$} & 0 & Yes & $55(73.3 \%)$ & & & & & \\
\hline & & No & $133(70.7 \%)$ & $0.88(0.48-1.60)$ & n.s & $0.51(0.45-0.57)$ & & \\
\hline \multirow{2}{*}{$\begin{array}{l}\text { Medial collat- } \\
\text { eral ligament }\end{array}$} & 0 & Yes & $7(53.8 \%)$ & & & & & \\
\hline & & No & $181(72.4 \%)$ & $2.25(0.73-6.93)$ & n.s & $0.52(0.49-0.56)$ & & \\
\hline \multirow{2}{*}{$\begin{array}{l}\text { Lateral collat- } \\
\text { eral ligament }\end{array}$} & 0 & Yes & $1(100.0 \%)$ & & & & & \\
\hline & & No & $187(71.4 \%)$ & $\begin{array}{l}0.00(0.00-\text { infin- } \\
\text { ity) }\end{array}$ & n.s & $0.50(0.50-0.51)$ & & \\
\hline \multirow{2}{*}{$\begin{array}{l}\text { Meniscus } \\
\text { (medial or } \\
\text { lateral) }\end{array}$} & 0 & Yes & $86(74.1 \%)$ & & & & & \\
\hline & & No & $102(69.4 \%)$ & $0.79(0.46-1.36)$ & n.s & $0.53(0.46-0.59)$ & & \\
\hline \multicolumn{9}{|c|}{ Surgery-related factors } \\
\hline \multirow[t]{2}{*}{ Graft choice } & 7 & $\begin{array}{l}\text { Hamstring } \\
\text { tendon }\end{array}$ & $173(74.6 \%)$ & & & & & \\
\hline & & Patella tendon & $14(48.3 \%)$ & $0.32(0.15-0.70)$ & 0.0043 & $0.56(0.51-0.61)$ & $0.25(0.11-0.57)$ & 0.0033 \\
\hline \multicolumn{9}{|c|}{ Patient demographics } \\
\hline \multirow{3}{*}{$\begin{array}{l}\text { Age at index } \\
\text { ACL recon- } \\
\text { struction (OR } \\
\text { per } 10 \text { units) }\end{array}$} & 0 & $12-<25$ & $98(82.4 \%)$ & & & & & \\
\hline & & $25-<35$ & $53(62.4 \%)$ & & & & & \\
\hline & & $35-58$ & $37(62.7 \%)$ & $0.76(0.60-0.98)$ & 0.034 & $0.60(0.52-0.67)$ & $0.73(0.56-0.94)$ & 0.017 \\
\hline \multirow[t]{2}{*}{ Patient sex } & 0 & Female & $86(69.4 \%)$ & & & & & \\
\hline & & Male & $102(73.4 \%)$ & $1.22(0.71-2.08)$ & n.s & $0.52(0.46-0.59)$ & & \\
\hline \multirow{5}{*}{$\begin{array}{l}\text { Tegner activ- } \\
\text { ity scale } \\
\text { pre-operative } \\
(0-10)\end{array}$} & 9 & $1-6$ & $51(63.0 \%)$ & & & & & \\
\hline & & 7 & $29(70.7 \%)$ & & & & & \\
\hline & & 8 & $41(74.5 \%)$ & & & & & \\
\hline & & 9 & $38(73.1 \%)$ & & & & & \\
\hline & & 10 & $21(84.0 \%)$ & $1.13(1.00-1.28)$ & $\mathrm{n} . \mathrm{s}$ & $0.58(0.51-0.66)$ & & \\
\hline \multirow{3}{*}{$\begin{array}{l}\text { Height }(\mathrm{cm}) \\
\quad(\text { OR per } 10 \\
\text { units) }\end{array}$} & 0 & $151-<170$ & $56(64.4 \%)$ & & & & & \\
\hline & & $170-<180$ & $71(83.5 \%)$ & & & & & \\
\hline & & $180-200$ & $61(67.0 \%)$ & $1.05(0.80-1.39)$ & n.s & $0.51(0.42-0.59)$ & & \\
\hline $\begin{array}{l}\text { Weight }(\mathrm{kg}) \\
\text { (OR per } 10 \\
\text { units) }\end{array}$ & 0 & $42-<67$ & $63(70.8 \%)$ & & & & & \\
\hline
\end{tabular}


Table 3 (continued)

\begin{tabular}{|c|c|c|c|c|c|c|c|c|}
\hline \multirow[t]{2}{*}{ Predictors } & \multirow[t]{2}{*}{$n$ missing } & \multirow[t]{2}{*}{ Value } & \multirow[t]{2}{*}{ Recovered "Yes" } & \multicolumn{3}{|l|}{ Univariable* } & \multicolumn{2}{|l|}{ Multivariable ${ }^{* * *}$} \\
\hline & & & & $\begin{array}{l}\text { OR }(95 \% \mathrm{CI}) \\
\text { LSI knee exten- } \\
\text { sion } \geq 90 \%\end{array}$ & $p$ value & $\begin{array}{l}\text { Area under ROC } \\
\text { curve }(95 \% \mathrm{CI})\end{array}$ & $\begin{array}{l}\text { OR }(95 \% \mathrm{CI}) \\
\text { LSI knee exten- } \\
\text { sion } \geq 90 \%\end{array}$ & $p$ value \\
\hline \multirow{5}{*}{ BMI $\left(\mathrm{kg} / \mathrm{m}^{2}\right)$} & & $67-<79$ & $67(77.9 \%)$ & & & & & \\
\hline & & $79-114$ & $58(65.9 \%)$ & $1.00(0.82-1.23)$ & n.s & $0.51(0.42-0.59)$ & & \\
\hline & & $16-<23$ & $73(70.9 \%)$ & & & & & \\
\hline & & $23-<25$ & $57(70.4 \%)$ & & & & & \\
\hline & & $25-39$ & $58(73.4 \%)$ & $1.00(0.91-1.10)$ & n.s & $0.49(0.41-0.57)$ & & \\
\hline
\end{tabular}

"Yes/No" indicates the presence of the described concomitant injury

$p$ values, OR and area under ROC curve are based on original values and not on stratified groups

$\mathrm{OR}$ is the ratio for the odds of an increase in the predictor of one unit

Area under ROC curve with 95\% CI for multivariable model $=0.62(0.55-0.68)$

$A C L$ anterior cruciate ligament, $O R$ odds ratio, $C I$ confidence interval, $R O C$ receiver operating characteristic

*All tests were performed with univariable logistic regression

***Multivariable logistic regression model including graft choice and lateral meniscus

to that achieving a symmetrical muscle function across a battery of tests is a difficult short-term goal to attain after ACL reconstruction [34], nonetheless, reflected by the low proportion of patients reaching this benchmark in the present study. It is, therefore, suggested that the results of this study should be taken into consideration when planning rehabilitation programmes and further emphasis should be placed on ensuring that compliance and intensity levels in training are kept appropriate to improve the recovery of muscle function after ACL reconstruction.

The LSI is one of the most common ways of presenting the outcome of tests of muscle function, as it facilitates an understanding of the results $[7,25]$. However, there is a possible overestimation of results when using measurements of limb symmetry to evaluate the recovery of knee function, even when rigorous RTS criteria are used, i.e. an LSI of $\geq 90 \%$ in multiple tests or the recovery of preinjury status [7, 11, 38]. Wellstandt et al. [38] evaluated the uninvolved limb as a reference standard for symmetry indices used in RTS testing. The authors found that estimated pre-injury levels of muscular strength and performance, based on tests conducted at an early stage after ACL injury, may be a better reference for the recovery of muscle function, considering the decrease in strength in the uninvolved limb that usually occurs during rehabilitation [38]. Over time, this reduction in the function of the uninvolved leg will inflate the LSIs and lead to a misrepresentation of the functional ability of the injured limb $[11,38]$. In addition, it should be pointed out that the LSI ratio is based on two independent tests, one on each limb, with their own variability. This makes the use of the LSI subject to uncertain variability which can over- or underestimate the true discrepancy between the patient's limbs. Not fulfilling the RTS criteria in five strength and hop tests has, which is of great clinical importance, been associated with a large increase in the risk of knee re-injury [21, 34]. Therefore, achieving symmetrical knee function after ACL reconstruction should be regarded as a fundamental goal of rehabilitation with regard to the protective effects of secondary injuries. However, it remains to be established whether this goal is sufficient to ensure a safe RTS and limit long-term impairments.

Graft choice between PT and HT autografts did not influence the likelihood of achieving symmetrical knee function. However, it should be noted that only a small proportion of patients $(n=25)$ received PT autografts, which induces uncertainty in the regression models, reflected by the wide confidence interval. Nevertheless, graft selection in ACL reconstruction is always accompanied by donor site morbidity impairing muscle function from the harvest site and creates morphological changes $[16,35]$. In particular, patients undergoing ACL reconstruction with PT autograft have been reported to have cellular alternations of the quadriceps, which may explain the difficulties in restoring knee extension strength in the short term $[24,35,40]$. This finding was consistent in both the univariable and multivariable analyses of the present study. In addition, favourable odds of achieving symmetrical knee extension strength were found in the presence of LM injury at ACL reconstruction, but this finding should be interpreted with caution. A meniscal injury is usually associated with pain and the limitation of the patient's 
Table 4 Univariable logistic regression model with a limb symmetry index of $\geq 90 \%$ in the knee flexion test as dependent outcome

\begin{tabular}{|c|c|c|c|c|c|c|}
\hline \multirow[t]{2}{*}{ Predictors } & \multirow[t]{2}{*}{$n$ missing } & \multirow[t]{2}{*}{ Value } & \multirow[t]{2}{*}{ Recovered "Yes" } & \multicolumn{3}{|l|}{ Univariable* } \\
\hline & & & & $\begin{array}{l}\text { OR }(95 \% \text { CI }) \text { LSI } \\
\text { knee flexion } \geq 90 \%\end{array}$ & $p$ value & $\begin{array}{l}\text { Area under ROC } \\
\text { curve }(95 \% \mathrm{CI})\end{array}$ \\
\hline \multicolumn{7}{|l|}{ Concomitant injuries } \\
\hline \multirow[t]{2}{*}{ Medial meniscus } & 0 & Yes & $38(66.7 \%)$ & & & \\
\hline & & No & $148(71.8 \%)$ & $1.28(0.68-2.39)$ & n.s & $0.52(0.46-0.58)$ \\
\hline \multirow[t]{2}{*}{ Lateral meniscus } & 0 & Yes & $47(65.3 \%)$ & & & \\
\hline & & No & $139(72.8 \%)$ & $1.42(0.80-2.54)$ & n.s & $0.54(0.47-0.60)$ \\
\hline \multirow[t]{2}{*}{ Articular cartilage } & 0 & Yes & $55(73.3 \%)$ & & & \\
\hline & & No & $131(69.7 \%)$ & $0.84(0.46-1.52)$ & n.s & $0.52(0.46-0.58)$ \\
\hline \multirow[t]{2}{*}{ Medial collateral ligament } & 0 & Yes & $10(76.9 \%)$ & & & \\
\hline & & No & $176(70.4 \%)$ & $0.71(0.19-2.67)$ & n.s & $0.51(0.48-0.53)$ \\
\hline \multirow[t]{2}{*}{ Lateral collateral ligament } & 0 & Yes & $1(100.0 \%)$ & & & \\
\hline & & No & $185(70.6 \%)$ & 0.00 (0.00-infinity) & n.s & $0.50(0.50-0.51)$ \\
\hline \multirow[t]{2}{*}{ Meniscus (medial or lateral) } & 0 & Yes & $77(66.4 \%)$ & & & \\
\hline & & No & $109(74.1 \%)$ & $1.45(0.85-2.48)$ & n.s & $0.55(0.48-0.61)$ \\
\hline \multicolumn{7}{|l|}{ Surgery-related factors } \\
\hline \multirow[t]{2}{*}{ Graft choice } & 7 & Hamstring tendon & $160(69.0 \%)$ & & & \\
\hline & & Patellar tendon & $25(86.2 \%)$ & $2.81(0.94-8.38)$ & n.s & $0.54(0.51-0.58)$ \\
\hline \multicolumn{7}{|l|}{ Patient demographics } \\
\hline \multirow{3}{*}{$\begin{array}{l}\text { Age at index ACL reconstruction (OR per } \\
10 \text { units) }\end{array}$} & 0 & $12-<25$ & $87(73.1 \%)$ & & & \\
\hline & & $25-<35$ & $63(74.1 \%)$ & & & \\
\hline & & $35-58$ & $36(61.0 \%)$ & $0.87(0.68-1.11)$ & n.s & $0.53(0.45-0.61)$ \\
\hline \multirow[t]{2}{*}{ Patient sex } & 0 & Female & $81(65.3 \%)$ & & & \\
\hline & & Male & $105(75.5 \%)$ & $1.64(0.96-2.80)$ & n.s & $0.56(0.50-0.63)$ \\
\hline \multirow[t]{5}{*}{ Tegner activity scale pre-operative $(0-10)$} & 34 & $1-6$ & $51(63.0 \%)$ & & & \\
\hline & & 7 & $32(78.0 \%)$ & & & \\
\hline & & 8 & $36(65.5 \%)$ & & & \\
\hline & & 9 & $41(78.8 \%)$ & & & \\
\hline & & 10 & $21(84.0 \%)$ & $1.14(1.01-1.29)$ & 0.037 & $0.59(0.51-0.66)$ \\
\hline \multirow[t]{3}{*}{ Height (cm) (OR per 10 units) } & 0 & $151-<170$ & $57(65.5 \%)$ & & & \\
\hline & & $170-<180$ & $61(71.8 \%)$ & & & \\
\hline & & $180-200$ & $68(74.7 \%)$ & $1.22(0.92-1.62)$ & n.s & $0.55(0.47-0.63)$ \\
\hline \multirow[t]{3}{*}{ Weight (kg) (OR per 10 units) } & 0 & $42-<67$ & $55(61.8 \%)$ & & & \\
\hline & & $67-<79$ & $66(76.7 \%)$ & & & \\
\hline & & $79-114$ & $65(73.9 \%)$ & $1.19(0.96-1.47)$ & n.s & $0.57(0.49-0.64)$ \\
\hline \multirow[t]{3}{*}{$\operatorname{BMI}\left(\mathrm{kg} / \mathrm{m}^{2}\right)$} & 0 & $16-<23$ & $70(68.0 \%)$ & & & \\
\hline & & $23-<25$ & $58(71.6 \%)$ & & & \\
\hline & & $25-39$ & $58(73.4 \%)$ & $1.06(0.96-1.17)$ & n.s & $0.54(0.46-0.61)$ \\
\hline
\end{tabular}

"Yes/No" indicates the presence of the described concomitant injury

$p$ values, OR and area under ROC curve are based on original values and not on stratified groups

$\mathrm{OR}$ is the ratio for the odds of an increase in the predictor of one unit

$A C L$ anterior cruciate ligament, $O R$ odds ratio, $C I$ confidence interval, $R O C$ receiver operating curve

*All tests are performed with univariable logistic regression

knee joint [15] and, therefore, there is no reason to believe that the presence of such injury has a favourable effect on the recovery of muscle function $[10,20]$. There is a possibility that patients who sustained a concomitant LM injury underwent a different rehabilitation regime, with altered timelines and delayed onset of full weight bearing and strength training, but no data are kept on these variables in the registers. In the sensitivity analysis performed 
on the knee extension test, the favourable odds of achieving symmetrical performance were only found in patients who were evaluated with the isometric test. Only a small proportion of patients were evaluated with the isometric test, which may have biased the analysis and could partly explain the significant effect from the presence of LM injury. In addition, no association was found between meniscal injury and the recovery of symmetrical knee extension strength, when both medial and LM injuries were included.

\section{Limitations}

Pre-operative results of muscle function were not available for all the included patients, which may pose a limitation, as strength differences in patients with and without concomitant injuries may have been present before they were treated with reconstructive surgery. The presence of concomitant injures was analysed dichotomously at reconstruction and no attention was, therefore, paid to the potential differences in the surgical and rehabilitation treatment. Moreover, the lack of data on the size and severity of concomitant injuries may mean that the dichotomous analysis of concomitant injuries was not sensitive enough to identify differences in the recovery of muscle function and could act as a limitation in the study. In addition, a very small proportion of patients had an injury to either the medial $(n=18)$ or the lateral $(n=1)$ collateral ligaments which limits the ability to draw conclusions related to these injuries. Finally, the low values of the ROC curve analyses suggested that none of the predictors in the study can be regarded as strong, despite their potential influence on clinical practice.

To our knowledge, this is the first study to examine the effect of concomitant knee injuries present during ACL reconstruction on the recovery of muscle function one year after surgery. This study provides unique data, comprising detailed information and clinical outcome from physiotherapists and surgeons, in a large cohort of patients.

\section{Conclusion}

No negative effect on the short-term recovery of symmetrical performance in five tests of muscle function was found in the presence of intra-operatively identified concomitant injuries; in the present study, comprising data on patients who had undergone ACL reconstruction from two registers. However, fewer than one in four patients in the total cohort achieved an LSI of $\geq 90 \%$ across the battery of tests, which may have implications for RTS.
In addition, younger age and HT autografts were favourable in terms of the recovery of knee extension strength, but graft choice did not influence the possibility of symmetrical performance across all five tests of muscle function one year after ACL reconstruction.

Acknowledgements The authors thank biostatisticians Bengt Bengtsson and Nils-Gunnar Pehrsson from Statistiska Konsultgruppen for help with statistical analyses and advice in regard to interpretation of data and the Swedish National Knee Ligament Register for providing data.

Author contributions Authors EHS, ES, SB and KS have substantial contributed to the acquisition of data, analysis of data, and are responsible of drafting the work and revising it critically for important intellectual content. Authors AG, CT and FK have done substantial contributions to the conception and design of the work, including interpretation of data. Authors RT and JK have done large contributions to revise and design the manuscript. All authors have given their final approval of the manuscript to be published. In addition, all authors are in agreement to be accountable for all aspects of the work in ensuring that questions related to the accuracy or integrity of any part of the work are appropriately investigated and resolved.

Funding This study did not receive any funding.

\section{Compliance with ethical standards}

Conflict of interest Each author certifies that he or she has no commercial associations (e.g. consultancies, stock ownership, equity interest, patent/licensing arrangements, etc) that might pose a conflict of interest in connection with the submitted article.

Ethical approval Ethical approval for this study was obtained from the Regional Ethical Review Board in Gothenburg (registration number 265-13, T023-17).

Open Access This article is distributed under the terms of the Creative Commons Attribution 4.0 International License (http://creativeco mmons.org/licenses/by/4.0/), which permits unrestricted use, distribution, and reproduction in any medium, provided you give appropriate credit to the original author(s) and the source, provide a link to the Creative Commons license, and indicate if changes were made.

\section{References}

1. Ahlden M, Samuelsson K, Sernert N, Forssblad M, Karlsson J, Kartus J (2012) The Swedish national anterior cruciate ligament register: a report on baseline variables and outcomes of surgery for almost 18,000 patients. Am J Sports Med 40(10):2230-2235

2. Almosnino S, Stevenson JM, Bardana DD, Diaconescu ED, Dvir Z (2012) Reproducibility of isokinetic knee eccentric and concentric strength indices in asymptomatic young adults. Phys Ther Sport 13(3): 156-162

3. Ardern CL, Glasgow P, Schneiders A, Witvrouw E, Clarsen B, Cools A, Gojanovic B, Griffin S, Khan KM, Moksnes H, Mutch SA, Phillips N, Reurink G, Sadler R, Silbernagel KG, Thorborg K, Wangensteen A, Wilk KE, Bizzini M (2016) 2016 Consensus statement on return to sport from the first world congress in sports physical therapy, Bern. Br J Sports Med 50(14):853-864 
4. Buckwalter JA (1983) Articular cartilage. Instr Course Lect 32:349-370

5. Buckwalter JA, Mankin HJ, Grodzinsky AJ (2005) Articular cartilage and osteoarthritis. Instr Course Lect 54:465-480

6. Creighton DW, Shrier I, Shultz R, Meeuwisse WH, Matheson GO (2010) Return-to-play in sport: a decision-based model. Clin J Sport Med 20(5):379-385

7. Dingenen B, Gokeler A (2017) Optimization of the returnto-sport paradigm after anterior cruciate ligament reconstruction: a critical step back to move forward. Sports Med 47(8):1487-1500

8. Drouin JM, Valovich-mcLeod TC, Shultz SJ, Gansneder BM, Perrin DH (2004) Reliability and validity of the Biodex system 3 pro isokinetic dynamometer velocity, torque and position measurements. Eur J Appl Physiol 91(1):22-29

9. Emilsson L, Lindahl B, Koster M, Lambe M, Ludvigsson JF (2015) Review of 103 Swedish healthcare quality registries. J Intern Med 277(1):94-136

10. Englund M, Roemer FW, Hayashi D, Crema MD, Guermazi A (2012) Meniscus pathology, osteoarthritis and the treatment controversy. Nat Rev Rheumatol 8(7):412-419

11. Gokeler A, Welling W, Benjaminse A, Lemmink K, Seil R, Zaffagnini S (2017) A critical analysis of limb symmetry indices of hop tests in athletes after anterior cruciate ligament reconstruction: a case control study. Orthop Traumatol Surg Res 103(6):947-951

12. Grindem H, Snyder-Mackler L, Moksnes H, Engebretsen L, Risberg MA (2016) Simple decision rules can reduce reinjury risk by $84 \%$ after ACL reconstruction: the Delaware-Oslo ACL cohort study. Br J Sports Med 50(13):804-808

13. Gustavsson A, Neeter C, Thomeé P, Silbernagel KG, Augustsson J, Thomeé R, Karlsson J (2006) A test battery for evaluating hop performance in patients with an ACL injury and patients who have undergone ACL reconstruction. Knee Surg Sports Traumatol Arthrosc 14(8):778-788

14. Hamrin Senorski E, Samuelsson K, Thomee C, Beischer S, Karlsson J, Thomee R (2017) Return to knee-strenuous sport after anterior cruciate ligament reconstruction: a report from a rehabilitation outcome registry of patient characteristics. Knee Surg Sports Traumatol Arthrosc 25(5):1364-1374

15. Kim SG, Nagao M, Kamata K, Maeda K, Nozawa M (2013) Return to sport after arthroscopic meniscectomy on stable knees. BMC Sports Sci Med Rehabil 5(1):23

16. Konrath JM, Vertullo CJ, Kennedy BA, Bush HS, Barrett RS, Lloyd DG (2016) Morphologic characteristics and strength of the hamstring muscles remain altered at 2 years after use of a hamstring tendon graft in anterior cruciate ligament reconstruction. Am J Sports Med 44(10):2589-2598

17. Kvist J, Kartus J, Karlsson J, Forssblad M (2014) Results from the Swedish national anterior cruciate ligament register. Arthroscopy 30(7):803-810

18. Kyritsis P, Bahr R, Landreau P, Miladi R, Witvrouw E (2016) Likelihood of ACL graft rupture: not meeting six clinical discharge criteria before return to sport is associated with a four times greater risk of rupture. Br J Sports Med 50(15):946-951

19. Lai CCH, Ardern CL, Feller JA, Webster KE (2018) Eightythree per cent of elite athletes return to preinjury sport after anterior cruciate ligament reconstruction: a systematic review with meta-analysis of return to sport rates, graft rupture rates and performance outcomes. Br J Sports Med 52(2):128-138

20. LaPrade CM, Dornan GJ, Granan LP, LaPrade RF, Engebretsen L (2015) Outcomes after anterior cruciate ligament reconstruction using the Norwegian knee ligament registry of 4691 patients: how does meniscal repair or resection affect short-term outcomes? Am J Sports Med 43(7):1591-1597
21. Lynch AD, Logerstedt DS, Grindem H, Eitzen I, Hicks GE, Axe MJ, Engebretsen L, Risberg MA, Snyder-Mackler L (2015) Consensus criteria for defining 'successful outcome' after ACL injury and reconstruction: a Delaware-Oslo ACL cohort investigation. Br J Sports Med 49(5):335-342

22. Mine T, Kimura M, Sakka A, Kawai S (2000) Innervation of nociceptors in the menisci of the knee joint: an immunohistochemical study. Arch Orthop Trauma Surg 120(3-4):201-204

23. Neeter C, Gustavsson A, Thomeé P, Augustsson J, Thomeé R, Karlsson J (2006) Development of a strength test battery for evaluating leg muscle power after anterior cruciate ligament injury and reconstruction. Knee Surg Sports Traumatol Arthrosc 14(6):571-580

24. Noehren B, Andersen A, Hardy P, Johnson DL, Ireland ML, Thompson KL, Damon B (2016) Cellular and morphological alterations in the vastus lateralis muscle as the result of ACL injury and reconstruction. J Bone Joint Surg Am 98(18):1541-1547

25. Noyes FR, Barber SD, Mangine RE (1991) Abnormal lower limb symmetry determined by function hop tests after anterior cruciate ligament rupture. Am J Sports Med 19(5):513-518

26. Nwachukwu BU, Anthony SG, Lin KM, Wang T, Altchek DW, Allen AA (2017) Return to play and performance after anterior cruciate ligament reconstruction in the National Basketball Association: surgeon case series and literature review. Phys Sportsmed 45(3):303-308

27. Oiestad BE, Engebretsen L, Storheim K, Risberg MA (2009) Knee osteoarthritis after anterior cruciate ligament injury: a systematic review. Am J Sports Med 37(7):1434-1443

28. Oiestad BE, Holm I, Aune AK, Gunderson R, Myklebust G, Engebretsen L, Fosdahl MA, Risberg MA (2010) Knee function and prevalence of knee osteoarthritis after anterior cruciate ligament reconstruction: a prospective study with $10-15$ years of follow-up. Am J Sports Med 38(11):2201-2210

29. Olsson O, Isacsson A, Englund M, Frobell RB (2016) Epidemiology of intra- and peri-articular structural injuries in traumatic knee joint hemarthrosis_-data from 1145 consecutive knees with subacute MRI. Osteoarthr Cartil 24(11):1890-1897

30. Risberg MA, Grindem H, Oiestad BE (2016) We Need to Implement current evidence in early rehabilitation programs to improve long-term outcome after anterior cruciate ligament injury. J Orthop Sports Phys Ther 46(9):710-713

31. Ruschel C, Haupenthal A, Jacomel GF, Fontana Hde B, Santos DP, Scoz RD, Roesler H (2015) Validity and reliability of an instrumented leg-extension machine for measuring isometric muscle strength of the knee extensors. J Sport Rehabil (Technical Notes 11). https://doi.org/10.1123/jsr.2013-0122

32. Sole G, Hamren J, Milosavljevic S, Nicholson H, Sullivan SJ (2007) Test-retest reliability of isokinetic knee extension and flexion. Arch Phys Med Rehabil 88(5):626-631

33. Tegner Y, Lysholm J (1985) Rating systems in the evaluation of knee ligament injuries. Clin Orthop Relat Res 198:43-49

34. Thomee R, Kaplan Y, Kvist J, Myklebust G, Risberg MA, Theisen D, Tsepis E, Werner S, Wondrasch B, Witvrouw E (2011) Muscle strength and hop performance criteria prior to return to sports after ACL reconstruction. Knee Surg Sports Traumatol Arthrosc 19(11):1798-1805

35. Thomee R, Neeter C, Gustavsson A, Thomee P, Augustsson J, Eriksson B, Karlsson J (2012) Variability in leg muscle power and hop performance after anterior cruciate ligament reconstruction. Knee Surg Sports Traumatol Arthrosc 20(6):1143-1151

36. Undheim MB, Cosgrave C, King E, Strike S, Marshall B, Falvey E, Franklyn-Miller A (2015) Isokinetic muscle strength and readiness to return to sport following anterior cruciate ligament 
reconstruction: is there an association? A systematic review and a protocol recommendation. Br J Sports Med 49(20):1305-1310

37. Walden M, Hagglund M, Magnusson H, Ekstrand J (2016) ACL injuries in men's professional football: a 15-year prospective study on time trends and return-to-play rates reveals only $65 \%$ of players still play at the top level 3 years after ACL rupture. Br J Sports Med 50(12):744-750

38. Wellsandt E, Failla MJ, Snyder-Mackler L (2017) Limb symmetry indexes can overestimate knee function after anterior cruciate ligament injury. J Orthop Sports Phys Ther 47(5):334-338

39. Wilson AS, Legg PG, McNeur JC (1969) Studies on the innervation of the medial meniscus in the human knee joint. Anat Rec 165(4):485-491

\section{Affiliations}

\section{Eric Hamrin Senorski ${ }^{1,2}$ (D) . Eleonor Svantesson ${ }^{3} \cdot$ Susanne Beischer $^{1,2} \cdot$ Christoffer Thomeé $^{2} \cdot$ Alberto Grassi $^{4}$. Ferid Krupic $^{3} \cdot$ Roland Thomeé $^{1,2} \cdot$ Jón Karlsson ${ }^{3,5} \cdot$ Kristian Samuelsson $^{3,5}$}

1 Department of Health and Rehabilitation, Institute of Neuroscience and Physiology, The Sahlgrenska Academy, University of Gothenburg, Gothenburg, Sweden

2 Sportrehab, Sport Medicine Clinic, Gothenburg, Sweden

3 Department of Orthopaedics, Institute of Clinical Sciences, The Sahlgrenska Academy, University of Gothenburg, Gothenburg, Sweden
40. Yazdanshenas H, Madadi F, Madadi F, Washington ER 3rd, Jones K, Shamie AN (2015) Patellar tendon donor-site healing during 6 and 12 months after anterior cruciate ligament reconstruction. J Orthop 12(4):179-183

41. Zwolski C, Schmitt LC, Quatman-Yates C, Thomas S, Hewett TE, Paterno MV (2015) The influence of quadriceps strength asymmetry on patient-reported function at time of return to sport after anterior cruciate ligament reconstruction. Am J Sports Med 43(9):2242-2249
4 Clinica Ortopedica e Traumatologica II-Lab. di Biomeccanica, ed Innovazione Tecnologica, Istituto Ortopedico Rizzoli, Bologna, Italy

5 Department of Orthopaedics, Sahlgrenska University Hospital, Mölndal, Sweden 